(Table). Receiver operating characteristic curves showed that M-DAS28, DAS28 (CRP) and RAPID3 had higher predictive value (area under the curve) than CDAI or SDAI for radiographic progression at M12 and M24 (Table). There was no impact of treatment arm on predictors of radiographic outcomes.

Conclusions: In this post hoc analysis, disease activity scores at baseline according to M-DAS28, DAS28 (CRP) and RAPID3 were good predictors of radiographic progression at M12 and M24 and were more predictive than other measures of disease activity tested, with M-DAS28 demonstrating the greatest degree of prediction.

References:

[1] Yazici Y, et al. J Rheumatol 2008;35:603-9.

[2] Salaffi F, et al. BMC Musculoskelet Disord 2011;12:120.

[3] Baker JF, et al. Arthritis Rheumatol 2014;66:794-802.

[4] Schiff M, et al. Ann Rheum Dis 2014;73:86-94.

Disclosure of Interest: E. Keystone Grant/research support from: Abbott, Amgen, AstraZeneca, Bristol-Myers Squibb, F. Hoffmann-La Roche, Janssen, Lilly, Novartis, Pfizer, sanofi-aventis, UCB, Consultant for: Abbott, AstraZeneca, Biotest, Bristol-Myers Squibb, Crescendo, F. Hoffmann-La Roche, Genentech, Janssen, Lilly, Merck, Pfizer, UCB, Speakers bureau: Amgen, Abbott, AstraZeneca, BristolMyers Squibb, F. Hoffmann-La Roche, Janssen, Pfizer, Sanofi, Genzyme, UCB, H. Ahmad Shareholder of: Bristol-Myers Squibb, Employee of: Bristol-Myers Squibb, Y. Yazici Grant/research support from: Genentech, Celgene, Bristol-Myers Squibb, Consultant for: Genentech, Celgene, Bristol-Myers Squibb, E. Muratti Employee of: Bristol-Myers Squibb, J. Ye Shareholder of: Bristol-Myers Squibb, Employee of: Bristol-Myers Squibb, M. Bergman Shareholder of: Pfizer, Johnson \& Johnson, Consultant for: AbbVie, Bristol-Myers Squibb, Amgen, Celgene, Genentech, Pfizer, Janssen, Speakers bureau: Norvatis, Abbvie, Celegene

DOI: 10.1136/annrheumdis-2017-eular.1930

\section{THU0090 INFLUENCE OF AGE AT DISEASE ONSET ON CLINICAL, FUNCTIONAL, AND ULTRASONOGRAPHIC OUTCOMES IN A MONOCENTRIC EARLY RHEUMATOID ARTHRITIS COHORT}

E. Galuppi, I. Farina, C. De Giorgio, C.A. Scirè, M. Govoni. Department of Medical Sciences, UOC Rheumatology, University of Ferrara and Azienda Ospedaliero-Universitaria Sant'Anna, Ferrara, Italy

Background: Rheumatoid Arthritis (RA) onset may occur at any age and peaks in the fifth decade. Because the mean age of general population is continually increasing and since older age could impact on outcomes, late-onset RA (LORA) will probably become a relevant issue for health care system in the next future. A better characterization of LORA could help rheumatologist in the therapeutic decision-making process tailored on the individual patient.

Objectives: To investigate the relationship between age at disease onset and clinical, ultrasonographic and functional outcomes.

Methods: Early RA (ERA) patients fulfilling 2010 ACR/EULAR, with available clinical ad ultrasonographic follow-up of at least 1 year, who consecutively attended our Early Arthritis Clinic between 2009-2014, were retrospectively analyzed. Patients were pooled into 3 groups by age at RA onset: $<45$ years (young-onset RA [YORA] group 1), 45 to 60 years (intermediate-onset RA [IORA] group 2), and $>60$ years (late-onset RA [LORA] group 3). At baseline biological, functional and ultrasonographic data were recorded. The following items were compared at baseline and after 12 months from diagnosis: DAS28 $8_{\text {CRP }}$ remission rate, functional disability using the Health Assessment Questionnaire (HAQ), power doppler (PWD) score, Methotrexate (MTX) treatment, use of glucocorticoids (GCs).

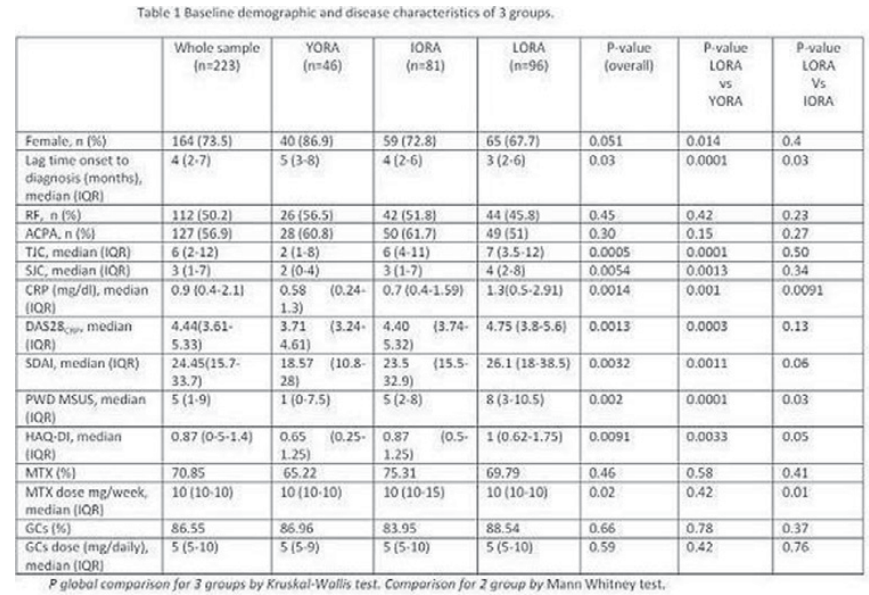

Table 2 Adjusted odds ratios (aORs) for $D A S 28$ Cw remission, PWO MSUS remission and HAQ score $<0.5$ at 1 vear follow up

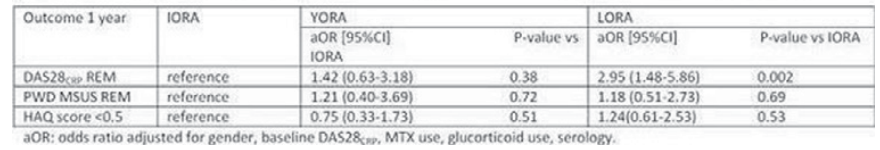

Results: The main baseline demographic and disease characteristics of the whole sample of ERA ( $n=223)$ and the 3 age groups- YORA (46), IORA (81) and LORA (96)- are summarised in Table 1. Age at RA-onset was independently associated with DAS28 $8_{\mathrm{CRP}}$ remission at 1 year (Table 2).

Conclusions: In a cohort of ERA, older age at disease onset is associated with a more active pattern disease at the beginning but with a greater probability of DAS28 ${ }_{\text {CRP }}$ remission at 1 year.

Disclosure of Interest: None declared

DOI: 10.1136/annrheumdis-2017-eular.5011

\section{THU0091 HIGH MULTI-BIOMARKER DISEASE ACTIVITY SCORE IS ASSOCIATED WITH HIGH RISK OF RADIOGRAPHIC PROGRESSION IN SIX STUDIES}

J.R. Curtis ${ }^{1}$, C.H. Brahe ${ }^{2}$, M. Ostergaard ${ }^{2}$, M.L. Hetland ${ }^{2}$, K. Hambardzumyan ${ }^{3}$, S. Saevarsdottir ${ }^{3}$, X. Wang ${ }^{4}$, E.H. Sasso ${ }^{4}$, T.W. Huizinga ${ }^{5}$. ${ }^{1}$ Univ. of Alabama at Birmingham, Birmingham, United States; ${ }^{2}$ Copenhagen Center for Arthritis Research, Copenhagen, Denmark; ${ }^{3}$ Karolinska Univ. Hospital and Karolinska Institutet, Stockholm, Sweden; ${ }^{4}$ Crescendo Bioscience Inc., South San Francisco, United States; ${ }^{5}$ Leiden Univ. Medical Center, Leiden, Netherlands

Background: The multi-biomarker disease activity (MBDA) test uses a validated algorithm with 12 serum protein biomarkers to assess disease activity in patients with RA. The MBDA score has previously been found to be a predictor of risk for radiographic progression (RP).

Objectives: To evaluate data from six cohorts to collectively establish the relationship between the MBDA score and risk for RP.

Methods: Clinical, MBDA score and radiographic data were analyzed for 6 cohorts with $\mathrm{N}>100$ : Leiden, SWEFOT Year 1, SWEFOT Year 2, OPERA Year 1, and AMPLE Year 1 (abatacept and adalimumab arms) (see Figure). Analyses used published results when available or patient-level data when not (i.e., for Leiden; and for OPERA CRP analyses). Frequency of RP over one year was determined by category of MBDA score (low, moderate [30-44], high on a scale of 1-100) at the start of the year for four cohorts and by category of MBDA score at the end of the year for AMPLE cohorts (as published). RP was defined using the threshold for change in total modified Sharp score ( $\triangle \mathrm{mTSS}$ ) specific to each study ( 2 to $>5$ TSS units). Positive and negative predictive values (PPV and NPV) were determined for each study by comparing patients with high MBDA score (>44), DAS28-(ESR/CRP) (>5.1 or $>4.09$ ) or CRP ( $>3 \mathrm{mg} / \mathrm{dL})$ vs. those in a not-high category. Relative risk (RR) for RP was determined for each study, and in a meta-analysis of the non-overlapping patient groups with MBDA scores available at the start of the year (Leiden, SWEFOT Year 1 and OPERA Year 1). Results of multivariate analyses and analyses that combined MBDA score with other risk factors for RP were summarized.

Results: The 6 study cohorts included patients receiving csDMARDs alone or with adalimumab, infliximab or abatacept. Overall rates of RP were $10-26 \%$. In each study, RP was most frequent among patients with a high vs. not-high MBDA score ( $>44$ vs. $\leq 44$ ). For high MBDA scores, NPVs were $93-97 \%$ and PPVs were $18-32 \%$, with RR values of $3.6-9.5$ ( $P=0.002$ to $<0.0001$ ) (Figure). In a meta-analysis of the Leiden, SWEFOT Year 1 and OPERA Year 1 cohorts, RR was $5.1(P<0.0001)$ for MBDA categories, and $1.4(P=0.23)$ and $1.6(P=0.01)$ for categories of DAS28-CRP or CRP, respectively. Previously published multivariate analyses in the Leiden and SWEFOT Year 1 cohorts showed that MBDA score was an independent predictor of RP compared with other predictors. In the Leiden cohort, MBDA score was the strongest predictor and high MBDA score

\begin{tabular}{|c|c|c|c|c|c|c|c|}
\hline \multicolumn{8}{|c|}{ Association between radiographic progression (RP) and high MBDA score (>44) } \\
\hline Cohort & $\mathbf{N}$ & $\begin{array}{l}\text { RP } \\
\text { cutoff }\end{array}$ & $\begin{array}{l}\text { Overall } \\
\text { \% RP }\end{array}$ & $\begin{array}{l}\text { PPV for } \\
\text { MBDA }>44\end{array}$ & $\begin{array}{l}\text { NPV for } \\
M B D A>44\end{array}$ & $\begin{array}{l}\text { Relative Risk }^{1} \\
\quad(95 \% \mathrm{Cl})\end{array}$ & P-value \\
\hline Leiden & 163 & $>5.0$ & $17 \%$ & $31 \%$ & $93 \%$ & $\begin{array}{c}4.3 \\
(1.9,9.5)\end{array}$ & $<0.0001$ \\
\hline $\begin{array}{l}\text { OPERA } \\
\text { Year } 1\end{array}$ & 164 & 22.0 & $26 \%$ & $31 \%$ & $97 \%$ & $\begin{array}{c}9.5 \\
(1.4,66.3)\end{array}$ & 0.0009 \\
\hline $\begin{array}{l}\text { SWEFOT } \\
\text { Year } 1\end{array}$ & 235 & $>5.0$ & $18 \%$ & $21 \%$ & $97 \%$ & $\begin{array}{c}7.1 \\
(1.0,49.9)\end{array}$ & 0.008 \\
\hline \multicolumn{6}{|c|}{ Meta-analysis (LEIDEN + OPERA Year $1+$ SWEFOT Year 1 ) } & $\begin{array}{c}5.1^{3} \\
(2.5,10.1)\end{array}$ & $<0.0001$ \\
\hline $\begin{array}{l}\text { SWEFOT } \\
\text { Year } 2\end{array}$ & 133 & $>5.0$ & $13 \%$ & $32 \%$ & $95 \%$ & $\begin{array}{c}6.2 \\
(2.4,16.5)\end{array}$ & 0.0001 \\
\hline $\begin{array}{l}\text { AMPLE } \\
\text { Year } 1 \text { (Aba) }\end{array}$ & 181 & $>2.2^{4}$ & $10 \%$ & $18 \%$ & $96 \%$ & $\begin{array}{c}4.5 \\
(1.6,13.1)\end{array}$ & 0.003 \\
\hline $\begin{array}{l}\text { AMPLE } \\
\text { Year } 1 \text { (Ada) }\end{array}$ & 186 & $>2.2^{4}$ & $11 \%$ & $24 \%$ & $93 \%$ & $\begin{array}{c}3.6 \\
(1.6,8.1)\end{array}$ & 0.002 \\
\hline
\end{tabular}

PPV, positive predictive value; NPV, negative predictive value. 1. Relative risk $=\mathrm{PPV} /(1-\mathrm{NPV}) .2$. Random-effect model used for meta-analysis. 3.Aggregated relative risk. 4. $\triangle T S S$ cutoff for RP was defined in Fleischmann et al (Arthritis Rheumatol 2016;68:2083-9) as >smallest detectable change (SDC), however no value was specified; SOC for AMPLE was specified as 2.8 and 2.2 in prior AMPLE publications (Weinblatt 2013; Schiff 2014).

Treatments; reference; data source:

LEIDEN (cSDMARDs); Li et al. Rheumatology (Oxford). 2013;55:357-66; Unpublished patient-level data only. OPERA (MTX+placebo-adalimumab+IA corticosteroids/MTX+adalimumab+IA corticosteroids); Brahe et al. Arthritis Rheumatol. ACR 2016 Abstract 2520; Published data and unpublished patient-level data for analysis of CRP categories.

SWEFOT Year 1 (MTX/triple therapy/MTX+infliximab); Hambardzumyan K, et al. Ann Rheum Dis. 2015;74:1102-9; Published data only.

2015;74:1102-9; Published data only.
SWEFOT Year 2 (triple therapy/MTX+infliximab); Hambardzumyan K et al, RMD Open. $2016 \mathrm{Mar}$ SWEFOT Year 2 (triple therapy/MTX

1;2(1):e000197, Published data only.

AMPLE Year 1 (abatacept and adalimumab arms, analyzed separately); Fleischmann et al. Arthritis Rheumatol 2016;68:2083-9, Curtis et al. Arthritis Rheumatol. 2016 Nov 3. doi: 10.1002/art.39981 and *Fleischmann et al
Arthritis Rheumatol. 2016 Dec 19. DOI: 10.1002/art.40021; Published data only, from Fleischmann et al(*). 